\title{
Implement Innovation-driven Strategy to Build a System for the Transformation of Scientific and Technological Achievements -- an example of Yunnan Power Grid Corporation
}

\author{
Liu Yingjie ${ }^{1}$, Zhu Quancong ${ }^{2}$, Chen Dekai*3 \\ ${ }^{1}$ Yunnan Power Grid Co., Ltd., Kunming, Yunnan, 65011, China; \\ ${ }^{2}$ Electric Power Research Institute, Yunnan Power Grid Co., Ltd., Kunming, Yunnan, 650217, China; \\ ${ }^{3}$ Kunming Power Supply Bureau, Yunnan Power Grid Co., Ltd., Kunming, Yunnan, 65011, China;
}

\begin{abstract}
The paper analysed the necessity of building a system of transformation of scientific and technological achievements based on the Yunnan Power Grid. Building system of transformation of scientific and technological achievements in accordance with the state-owned enterprise development characteristics of concrete implementation measures. It can implement science and technology of the property to maintain or increase its value, reflect the talent to create value and improve employees' innovation and vigor and passion.
\end{abstract}

\section{INTRODUCTION}

Yunnan Power Grid Corporation has been adhering to the "science and technology innovation as the first productivity" concept of enterprise innovation which is the implementation of the strategy of "southeast Asia bridgehead-national strategy" important units. Transformation of scientific and technological achievements is the most effective way to make the role and value of the company's scientific and technological innovation. It extremely restricted and hindered the effectiveness of achievements because of asymmetric information, lacking of scientific feasibility evaluation and the problems of the support system even the state has provided a powerful policy guarantee.Therefore, it is necessary to establish a transformation management system that conforms to the development characteristics of state-owned enterprises such as management concepts, institutional policies, transformation channels and personnel training. It is an inevitable choice to enhance enterprises' self-help innovation ability and core competitiveness.

\section{The Necessity of Building a System}

The academic began to study the theory of (Technology Transfer) at the end of the 19th century and the beginning of the 20th century. In 1904, the French sociologist (Tarde) put forward the "S-diffusion" model. By the mid-1950s and 1960s, the achievements had been transformed into a mature and systematic scientific discipline combining theory with practice. The research perspective had shifted from sociology to economics ${ }^{[1]}$.

The research on the transformation system of scientific and technological achievements in China began in the 1970s. The system of the transformation of scientific and technological achievements involves the research and development parties, the transferee of the transformation of scientific and technological achievements, the government administration departments and the intermediary agencies. Also it influenced by the national policy environment, the financial environment and various aspects of society ${ }^{[2,3]}$. Currently, the academic discussion on the transformation of scientific and technological achievements mainly focuses on the definition of the transformation process of scientific and technological achievements and the research of the transformation system of scientific and technological achievements. However, there are few studies on the evaluation of the implementation effect of the policy on the transformation of scientific and technological achievements ${ }^{[4]}$.

Yunnan Power Grid Corporation construct technology achievement transformation system from system and safeguards to support the results of power grid industry through transformation to generate economic benefits and the implementation of science and technology of the property to maintain or increase its value.

\section{The main methods}

\subsection{Exploration of transformation approaches and system construction}

Focusing on the pain points and difficulties of state-owned enterprise technology innovation activities, Yunnan Power Grid Co. LTD issued "the study of transformation of scientific and technological achievements management system of Yunnan power grid company", "the study of transformation of scientific and technological 
achievements management system of Yunnan power grid company", "Yunnan power grid company scientific and technological achievements bonus incentive implementation rules" The company provided policy support for the transformation mode and process, procurement management and incentive mechanism. It has laid a solid political foundation for state-owned enterprises to carry out the transformation of scientific and technological achievements in a comprehensive. There was the first time opened up the transformation chain of scientific and technological achievements within the scope of Yunnan power grid company.

It has been written the Yunnan power grid corporation transformation of scientific and technological achievements management system study, introduced the measures for the management of Yunnan Power Grid co., LTD. Transformation of scientific and technological achievements of Yunnan power grid corporation share out bonus incentive detailed rules for the implementation of scientific and technological achievements specification workflow and rewards to the company rules, to establish the transformation of scientific and technological project wi into contract template achievements transformation process facilities, such as feasibility study report file conversion work responsibilities of various departments and units in the way and the process of purchasing management Clear reward mechanism, straighten out the management interface of transformation of scientific and technological achievements, make the transformation work, there are laws have a foundation for the follow-up work provides a complete systematic policy to support the overall transformation of scientific and technological achievements for state-owned enterprises laid a solid political foundation, and for the first time in yunnan power grid corporation through the transformation of scientific and technological achievements within the scope chain.

\subsection{Integrate internal and external resources of the power grid to expand the scope of innovation and effectiveness}

The transformation of scientific and technological achievements is a systematic project which requires crossdepartment, cross-field and cross-specialty cooperation. It needs to actively establish a linkage and cooperation mechanism with the company's legal and financial departments, form an effective and practical transformation service mode, strengthen the connection with external transfer and transformation technology institutions, and go out to learn from good experiences and practices. Please come in to strengthen the business training and improve the business level of the center personnel. In the links such as the identification and exemption of the transformation contract on the website of the patent license, the center personnel actively communicate with the functional institutions to learn the latest policy information and improve the efficiency of the transformation process, so as to effectively promote the development of the transformation work.

The economic benefits of output need to be translated into units except internal departments at all levels of the power grid. There are more than 360 large collective enterprises which give full play to its resources and industrial advantages. At the same time, Yunnan Power Grid Co. LTD held two science and technology achievement fairs successfully. The conversion of scientific and technological achievements were released the projects to be 123,23 company headquarters and molecular, 25 staff shareholding enterprises after the reform and 19 domestic famous manufacturer of electric power design a total of more than 300 people attended the event. It opened a new transformation chapter of scientific and technological achievements within the scope of the company set off a new boom from the transformation of scientific and technological innovation and achievements.

\subsection{Build a transformation platform to realize all- round management of achievement transformation}

To effectively broaden the achievements of information sources to gather network science and technology resources, promoting the transformation of achievements completed with effective docking, build the information service platform for transformation of scientific and technological achievements, big data using Internet ++ open service mode of science and technology and intelligent docking technology service platform architecture, using information technology to build the whole process of all-round transformation of scientific and technological achievements information integrated service platform, the digital and networked, scientific and technological achievements transformation of the achievements resources integrate mining processing and processing to realize online registration novelty assessment of scientific and technological achievements to negotiate the contract signing and other one-stop service, research and development for the investors producers marketers build Bridges and realize the whole process of industrialization of achievement of science and technology service tracking and standardize management in ascension work management level and shorten the cycle transformation has played a positive role in and try to continue making the platform company unified database and data service platform of scientific and technological achievements, the expansion of business scope gradually by the transformation of achievements achievements services to intellectual property service and technological achievements evaluation service information service of science and technology scientific and technological personnel service big data analytics cloud computing software development achievements transformation service platform construction of wide fields such as intelligent platform to open series efficient. We will upgrade and expand precision services.

Information platform of transformation of scientific and technological achievements of the design is shown in Figure 1. On the base of software development platform, the combination of science and technology project achievement library intelligent creation process research, It realize the scientific and technological achievements in the web services platform of automation and intelligent 
storage. Also, it Combined with the research on the data screening technology of scientific and technological project achievements based on intelligent intelligence collection and analysis. The platform provides the basic support for the evaluation and information release of

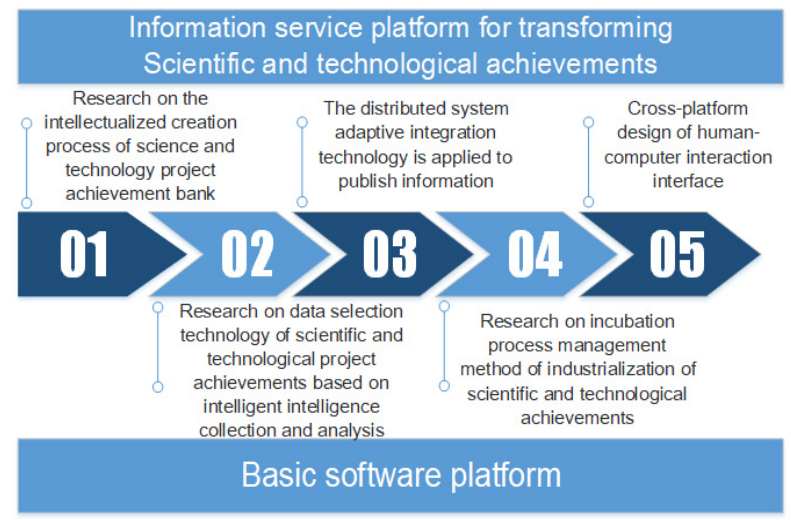

Fig1. Figure 1. structural design of the platform for transformation of scientific and technological achievements

and technological achievements. The distributed system adaptive integration technology is applied to release information, the information of scientific and technological achievements which is pushed through the network. The manufacturers with technical strength are widely recruited to sign up for cooperation. Through the design of cross-platform human-computer interaction, the platform can work in a variety of terminals online to improve the efficiency of the transformation of scientific and technological achievements.

\section{The innovation points}

(1) Through the exploration of transformation, a transformation system conforming to the development characteristics of state-owned enterprises is established to escort the opening up of the channel for scientific and technological innovation; Effectively integrate resources the power grid and expand the influence of innovation and efficiency;

(2) It has built an information service platform for the transformation of scientific and technological achievements. It realized the full-life management of the transformation of scientific and technological achievements. It effectively promoted the transformation results.

(3) It stimulated employees' enthusiasm for innovation by cashing bonus and dividends to realized the maintenance and appreciation of power grid technology assets; Set up a flag for management innovation in the power grid industry and injected new vitality into the company's digital transformation;

(4) Realized the maintenance and appreciation of power grid science and technology assets, and stimulated the innovation enthusiasm of employees by cashing the bonus;

(5) It has set a benchmark for management innovation in the power grid industry and injected new vitality into the digital transformation of the company.

\section{CONCLUSION}

It effectively promoted the application and commercialization of scientific and technological achievements and explored the transformation path for the scientific and technological achievements of many power supply units of Yunnan power grid company. In order to further establish a diversified and innovative industrial alliance with power grid achievements as the core, it will promote competitive enterprises in the grid system to focus on the development of competitive specialties. At the same time, the platform for the transformation of scientific and technological achievements was established in Yunnan power grid company.

It can effectively expand the source channels of information of achievements to gather scientific and technological resources of the power grid and promote the connection between the transformation party. It also realize the service tracking and standardized management of the whole process of the industrialization of scientific and technological achievements. There were 45 achievements have been successfully transformed which has accumulated economic benefits of more than 50 million yuan in Yunnan Power Grid Co. LTD.

\section{REFERENCES}

1. J R. HICKS A theory of economic history[M].Oxford University Press, 1969:86.

2. B H HALL, MONCADAPATERNOCASTELLO P, MONTRESOR S, et al. Fianancing constrains, R\&D investments and innovative performances: new emprirical evidence at the firm level for Europe[J].Economic of Innovation \& New Technology, 2016,(25):1-14.

3. A HOWELL.Firm R\&D,innovation and easing financial constraint in China:does corporate tax reform matter[J].Research Policy,2016,45(10):19962007.

4. Su ying. Empirical study on the coupling synergy between science and technology innovation and science and finance in China $[\mathrm{J}]$. Journal of yanshan university (philosophy and social sciences edition), 2019,20 (3) : 59-67. 